\title{
Correction to: Detection of circulating tumor DNA in cerebrospinal fluid prior to diagnosis of spinal cord lymphoma by flow cytometric and cytologic analyses
}

Chisako Iriyama $^{1} \cdot$ Kenichiro Murate $^{2} \cdot$ Sachiko Iba $^{1} \cdot$ Akinao Okamoto $^{1} \cdot$ Hideyuki Yamamoto $^{1} \cdot$ Ayana Kanbara $^{3}$. Akane Sato $^{3}$ - Emiko Iwata ${ }^{3} \cdot$ Ryuta Yamada $^{3} \cdot$ Masataka Okamoto $^{1} \cdot$ Hirohisa Watanabe $^{2} \cdot$ Tatsuro Mutoh $^{2}$. Akihiro Tomita ${ }^{1}$

Published online: 27 November 2021

๑) Springer-Verlag GmbH Germany, part of Springer Nature 2021

Correction to: Annals of Hematology

https://doi.org/10.1007/s00277-021-04686-7

Of the MRI photos shown in the upper part of Figure 1, the leftmost photo contained two inappropriate red arrows and an inappropriate white letter "M."

The original article has been corrected.

The original article can be found online at https://doi.org/10.1007/ s00277-021-04686-7.

Akihiro Tomita

atomita@fujita-hu.ac.jp

1 Department of Hematology, Fujita Health University

School of Medicine, 1-98 Dengakugakubo, Kutsukake-cho,

Toyoake, Aichi 470-1192, Japan

2 Department of Neurology, Fujita Health University School of Medicine, Toyoake, Japan

3 Department of Analytical Neurobiology, Faculty of Pharmacy, Meijo University, Nagoya, Japan 


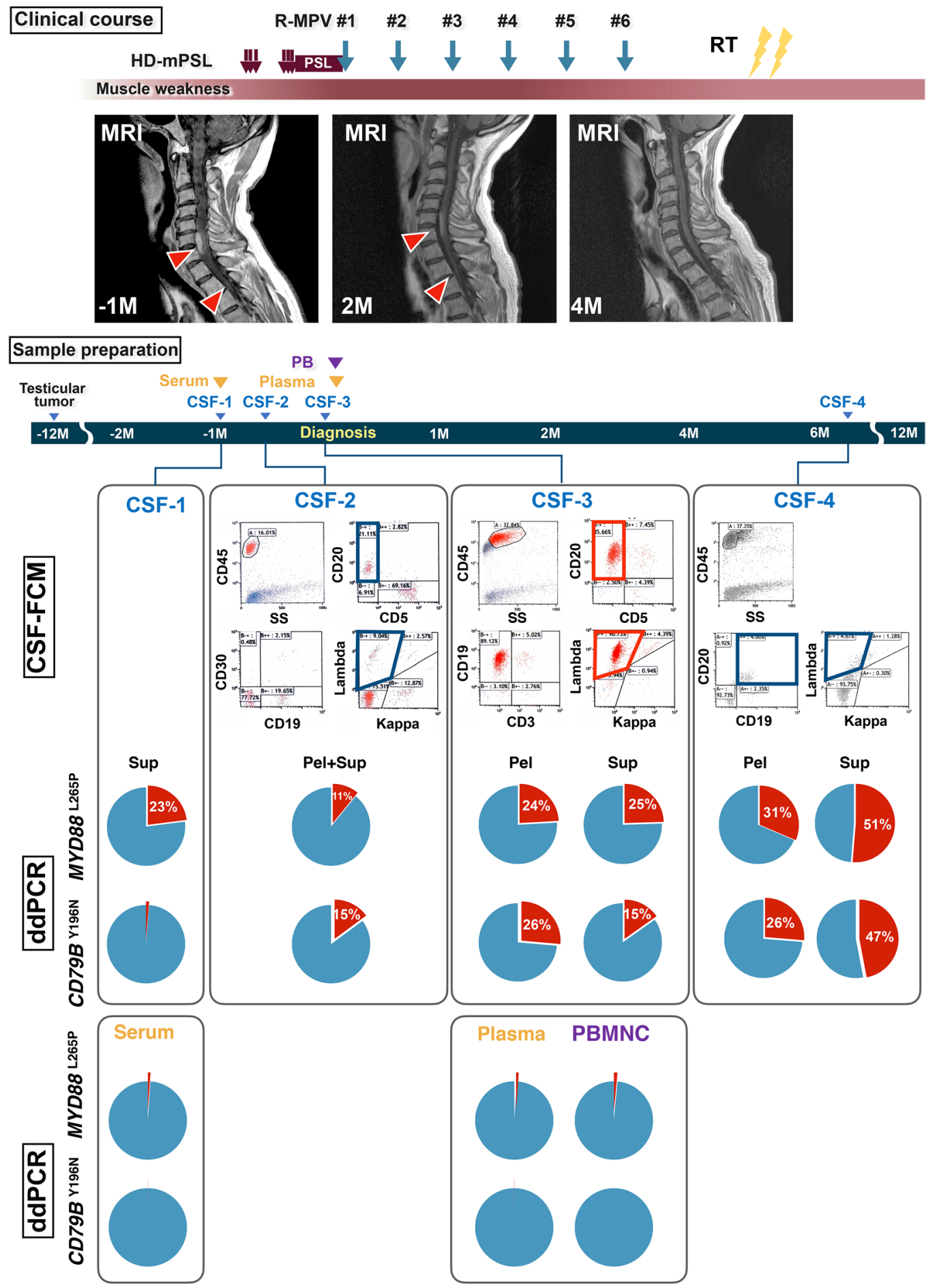

Publisher's note Springer Nature remains neutral with regard to jurisdictional claims in published maps and institutional affiliations. 